\title{
Documents and Publications of the United Nations
}

$\mathrm{T}$ WO YEARS ago in this city, on June 26 , 1945, the representatives of fifty-one governments signed the charter of the United Nations and the statute of the International Court of Justice. The six main organs of the United Nations have since been established, the eleven commissions of the Economic and Social Council have been set up, and the major relationships between the specialized agencies and the United Nations have been defined for most of the agencies by agreement so that the initial period of basic organization may be said to have been completed.

During these two years of efforts to revivify and coordinate international activities disrupted by the late war, to grapple with the first substantive problems laid before the United Nations, the Secretariat itself has been in process of organization. The work of building a new Secretariat, while at the same time serving the new organs engaged in their first tasks, has not been made easier by the two great removes of the organization, from London to the Bronx in New York City, and thence to Lake Success in Long Island, which in turn will be only a temporary headquarters until the erection of the permanent buildings on the East River site in Manhattan. It is not surprising, therefore, if the swirl of activities, sweeping across the Atlantic to the New World and back again through conferences and commissions of inquiry and new specialized agencies, has prevented Sec-

1 Paper presented at the meeting of the Public 1 Paper presented at the meeting of the Public
Documents Committee, San Francisco, July 2, I 947 . retariat procedure from settling into recognizable patterns which may be described and cataloged with assurance. For the methodically-minded observer, the situation is still not clear, and to the Secretariat itself only the grander outlines and some details here and there emerge with clarity. But we are beginning to see our way and to order and coordinate our activities. It will be reasonable enough, therefore, simply to outline in this paper the situation concerning documents and publications of the United Nations, without pretending to finality in description.

\section{Definitions}

Certain definitions may be conveniently laid down and certain areas marked off as outside the scope of the present paper. The term "United Nations documents" covers only those papers submitted, records of meetings, resolutions and reports adopted by organs and suborgans of the United Nations, which are published in a series under an official symbol or in the official records, whether the distribution be unrestricted or restricted, whether the documents be processed or printed. Drafts, internal Secretariat studies, and delegation papers which are not so published or which remain in typescript are excluded from that definition. Press releases and publications of the Department of Public Information, of the Statistical Office of the United $\mathrm{Na}$ tions, and of other divisions of the Secretariat are likewise excluded. Furthermore, of the documents and publications of the 
United Nations, four groups will not be described in this paper. (I) The documents of the specialized agencies are outside the scheme of documentation developed at the headquarters. The specialized agencies are relatively autonomous and vary considerably in their methods of documentation, publication, and distribution. Some agencies, such as the International Labour Organization, are older than the United Nations itself; others, such as the International Refugee Organization, are not yet completely established; and most of them are not seated at the headquarters.

The documents of the Military Staff Committee are produced and distributed by that body alone. (3) The circulars and bulletins of the Secretariat are primarily of internal interest and circulation. (4) The documents issued away from headquarters, at the European office in Geneva, for example, have not yet been received with sufficient speed and regularity for the Documents Index unit at the headquarters to make any reasonable observations in the matter.

The documents of the International Court of Justice, which is seated at The Hague, lie outside the scheme of publications and distribution developed at the headquarters. They are printed in Leiden and are distributed by the court, which will, however, use the regular sales agents of the United Nations. Six series are planned: A. Judgments; B. Advisory opinions; C. Documents presented in cases; D. Statutes and treaties governing the organization of the court; E. Annual reports; F. Indexes to the judgments, etc. So far, only the first number in Series D has appeared.

\section{Documents Series}

Returning to an outline of the present situation with respect to United Nations documentation for the General Assembly, the councils, and commissions, we may ob- serve that there are several salient categories by which it may be described. First, documents appear on paper of a distinctive color and masthead and under a series symbol. Second, nearly all documents are issued both in English and in French, the working languages, and key documents usually appear also in Russian, Spanish, and Chinese editions. Third, most documents issued for current use in discussion are processed (mimeograph or offset reproduction), a fact which sets a limit to the quantity which may be produced and which under the present distribution policy excludes such processed documents from sale, in order to assure an adequate supply for official use. Fourth, a considerable number of documents are reissued in printed form in the official records of the various main organs, so that they are generally available to the public through sale or subscription; and, furthermore, a growing number of key reports, from the SecretaryGeneral and from subordinate bodies to the main organs, for instance, will appear initially in printed form either as separate documents in series or as separate supplements to official records of the main organ concerned. Fifth, documents are classified as to distribution into the categories "unrestricted," "restricted," and "secret." The last category requires the written approval of the Secretary-General for issue and so far has not been used. "Restricted" documents, including "restricted working papers," are circulated primarily to the members of the body of issue, usually a drafting subcommittee or body in which certain questions of policy are being initially discussed, or which meets in "closed" or "private" session. "Secret" and "restricted" documents are not distributed to the so-called depository libraries.

We may now take up in greater detail each of the five broad groupings outlined above. First, the identification of docu- 
ments. The use of colored sheets for processed documents and colored covers for printed documents permits quick recognition of the issuing body in rapid sorting of masses of documents, whatever may be thought of the variations in hue which arise from the present exigencies in the paper supplies. All documents in the General Assembly, its committees and other subordinate bodies appear on white paper under a bilingual General Assembly masthead. Documents of the Security Council and its subordinate bodies appear on yellow under a Security Council masthead. The documents of the Economic and Social Council and its commissions appear on blue paper (although the documents of the first session issued in London were pink). The Trusteeship Council documents are green. The important Atomic Energy Commission, although not one of the six main organs under the charter, issues documents on salmon paper. The Secretariat circulars and bulletins appear on white paper under a bilingual "United Nations" masthead, which is also used for documents of any joint body composed of representatives of two of the six main organs. The covers only of the official records of the General Assembly and the councils are colored in the distinctive manner just described. The former journals, however, were printed on paper of these distinctive colors, with the journal of the first session of the Economic and Social Council, like the documents of that London session, in pink. So far as one can at present see, this policy will remain unchanged.

The system of document series symbols is more complex. The present system was laid down in New York and modifies the arrangements prevalent in the London period by discarding emphasis on letter symbols for a system which is primarily numerical in character. The modifications are really less severe than they have appeared. Most of the purely alphabetical series symbols which were superseded relate either to documents of ad hoc committees which have been dissolved or to documents of the "nuclear" commissions of the Economic and Social Council which have been succeeded by full commissions regarded as new bodies. There remain to be sure, certain inconsistencies, but the following brief outline describes the basic features. Since the work of the main and subordinate organs during the years 1946 and 1947 has been essentially organizational in character, there is still, here and there, an area of uncertainty in symbol series of subordinate bodies, especially where certain bodies have not yet established a characteristic pattern of work and organization. Furthermore, anomalies have appeared and will appear when documents are produced away from the headquarters by members of the Secretariat not entirely familiar with the scheme.

Each of the main organs covered by the scheme and the Atomic Energy Commission has a characteristic symbol for its own plenary or general documents series: A/ for the General Assembly, S/ for the Security Council, E/ for the Economic and Social Council, T/ for the Trusteeship Council, and AEC/ for the Atomic Energy Commission. Documents presented to the main organ for consideration or issued by it are identified by a number following the characteristic basic symbol for the organ. Thus, $\mathrm{A} / \mathrm{I} 82$ is the $182 \mathrm{nd}$ document in the general series of the General Assembly, S/27 is the twenty-seventh document in the general series of the Security Council, and so on.

Subordinate to the General Assembly and the councils, is a ramifying complex of committees, commissions, subcommittees, and other bodies. Most of the permanent subordinate bodies have been now established, but there is no end to the number of ad hoc subordinate bodies which are created for specific tasks and are dissolved when these 
are accomplished. This is not the place to describe their documentation in detail, but the general scheme may be outlined rather simply, with the reminder that the present arrangements have superseded the initial pattern devised in London.

The documents of any permanent or standing committee of a main organ are identified by a symbol composed of the basic symbol for the main organ and the component for committee numbered to correspond with the particular committee. Thus documents of the first or Political and Security Committee of the General Assembly are identified by the symbol A/C.I/ ; the documents of the Committee on Arrangements for Consultation with Nongovernmental Organizations of the Economic and Social Council are identified by the symbol E/C.2/ .

Similarly, documents of ad hoc committees are identified by a symbol composed of the basic symbol for the main body and a component for the ad hoc committee numbered to correspond with the order of its establishment. Thus, E/AC.I7/ is the series symbol for the ad hoc Committee on the Economic Commission for Europe, the seventeenth ad hoc committee established by the Economic and Social Council. Committees appointed before the institution of the present symbol scheme have been counted in determining the number of ad hoc committees so far established, but their old alphabetical symbols remain unchanged since most of these committees have expired. The permanent headquarters Committee of the General Assembly (symbol, A/SITE/ ) was the second ad hoc committee to be established by the General Assembly but its documents will continue to bear the old symbol until the committee is discharged.

Subcommittee series are indicated by affixing the number symbol component /SC.I/, /SC.2/, etc., to the symbol for the parent committee or ad hoc committee.

Outside the Economic and Social Council proper are its subordinate commissions now numbering eleven. The documents of each of these are distinguished by a numbered component indicating a commission (/CN.I/ , /CN.2/, etc.) affixed to the basic symbol for the council. Thus the documents of the Economic and Employment Commission bear the symbol E/CN.I/ ; the Statistical Commission, the symbol E/CN.3/ ; the Population Commission, the symbol E/CN.9/. It was felt by the Documents Index unit that a numerical designation would be less confusing in the long run than purely alphabetical symbols, because the innumerable alphabetical designations for various national and intergovernmental bodies already in existence narrow the choice of meaningful letter combinations available, while the problem of creating letter symbols meaningful in both English and French further narrows the area of choice. In the case of the Economic Commission for Europe the series symbol E/CN.Io/ was overruled in favor of $\mathrm{E} / \mathrm{ECE} /$, but the latter symbol, completely alphabetical, may easily be confused by the unwary with the current abbreviation EECE for the Emergency Economic Committee for Europe, an older organization which is about to be dissolved.

Subcommissions series are indicated by affixing the numbered component /SUB. I, /SUB. 2, etc., to the series symbol for the parent body. Thus E/CN.4/SUB.2/ designates the Subcommission on Prevention of Discrimination and Protection of $\mathrm{Mi}$ norities established by the Commission on Human Rights.

Conferences under the auspices of the Economic and Social Council or its commissions have been variously designated, but henceforth, will be designated with a numbered conference component E/CONF. I/, E/CONF. 2/, etc. 
Preparatory committees established to prepare for such conferences will issue documents bearing the affix /PC/ attached to the conference symbol.

In addition to their general series, there are for most of the main organs and subordinate bodies, certain subseries also embracing information series, records of meetings, and working papers. The symbol components for these types of subseries are affixed to the basic symbol for the organ. Thus, instructions to delegations, lists of members of delegations, and similar purely informative documents are issued in an information series with the affixed secondary symbol /INF/, so that the symbol $\mathrm{A} / \mathrm{INF} / 3$ is to be interpreted as the third document in the information series of the General Assembly.

Records of meetings appear either as verbatim records with the affixed secondary symbol / PV., indicating procès-verbal in extenso, or as summary records with the affixed secondary symbol /SR., indicating summary record, so numbered that the document number corresponds with the meeting number in a continuous series. Thus, S/PV.53 indicates the verbatim record of the fifty-third meeting of the Security Council, while T/AC.2/SR.6 indicates the summary record of the sixth meeting of the ad hoc Committee on Questionnaires established by the Trusteeship Council. It should be observed that verbatim records are provisional in character both as to original and interpreted text. They are prepared during the course of the plenary meetings for immediate issue to delegations, the Secretariat, and the press. Delegations are requested to forward any corrections within forty-eight hours to the Editorial Division, which is charged with preparing copy for the official records. The Economic and Social Council, unlike its sister organs, publishes only summary records in its Official Records (as formerly in its Journal), so that the verbatim records remain in processed form only. Beginning with the fifth session, the summary records of this council will appear in a summary record series, instead of being scattered through its plenary series. The General Assembly, the Security Council, the Atomic Energy Commission, and the Trusteeship Council, which reissue the final texts of their verbatim records in their official records, do not issue summary records of plenary meetings.

With the exception of the first special session of the General Assembly, and the public meetings of the Subcommittee on the Spanish Question of the Security Council, verbatim records are not published for committees, commissions, and other subordinate bodies of the main organs but remain in manuscript form (if verbatim reporters were available to record the proceedings) in the files of the Secretariat or in the archives of the United Nations. Committees, commissions, and other subordinate bodies which issue records of their proceedings publish summary records. So far, only the summary records of the committees of the General Assembly (with the exception of the Credentials Committee) have been reissued in the printed official records. The summary records of the committees, commissions, and other subordinate bodies of the councils, as well as the subcommittees of General Assembly committees remain in processed form.

The last of the subseries embraces the working papers, always of restricted distribution, and usually composed of drafts and other documents for preliminary consideration or for discussion in closed meetings. Such a subseries is indicated by affixing the secondary symbol $/ W$. to the basic symbol for the issuing body. The issue of such working papers is usually confined to committees and other subordinate bodies. Thus, document $\mathrm{A} / \mathrm{AC} .7 / \mathrm{W} .3$ is 
the third working paper of the headquarters Advisory Committee.

In addition to symbols for these subseries and to the series of subordinate bodies, certain other secondary symbols are employed to indicate revisions of texts and corrigenda and addenda.

When the text of a document has been formally revised by action of the issuing body, or a delegation or the Secretariat has prepared a revised text of a document submitted by it, the secondary symbol /Rev.I is added to the symbol and number assigned to the original text. Thus $\mathrm{E} / \mathrm{INF} / \mathrm{I} /$ Rev.I denotes the first revision of document one in the information series of the Economic and Social Council.

If new material is issued which should be appended to a document already published, such as an appendix, tables, charts, maps, additional clauses or paragraphs, later information and the like, the addendum is issued with the secondary symbol Add. I added to the original symbol and number of the main document. Thus $T / 15 /$ Add. I would be the first addendum to document fifteen in the general series of the Trusteeship Council. E/INF/I/Rev.I/ Add. I would be the first addendum to the first revision of document one in the information series of the Economic and Social Council.

Secretarial or editorial correction of errors in the text, title, date or classification of a document, including the emendation of the translation or the addition of text erroneously omitted may be accomplished by issuing a corrigendum bearing the secondary symbol /Corr. I attached to the original symbol and number of the main documents. Thus, S/PV.82/Corr.3 is the third corrigendum to the verbatim record of the eighty-second plenary meeting of the Security Council. The time has not yet arrived when the Secretariat may produce documents with an Olympian calm and de- cisiveness which precludes the necessity of issuing occasional revisions, corrigenda, and addenda, but the line is drawn at the issuance of corrigenda to corrigenda, and instead a second or third corrigendum is issued.

\section{Printed Documents}

Of the processed documents described above, many are destined to be reissued in the printed official records and in the supplements thereto. The official records of the General Assembly, of the Security Council, the Economic and Social Council, the Trusteeship Council, and the Atomic Energy Commission comprise the records of the plenary meetings. These are usually verbatim records, but in the case of the Economic and Social Council, they are summary records only. The supplements contain the principal documents discussed at these meetings. The official records will replace entirely the former journals of the General Assembly, the Security Council, and the Economic and Social Council, and the former Journal of the United Nations, all of which, like the processed verbatim records, are only provisional in character. It is true that a great backlog of older records has not been printed because of the priority given to the heavy demands for printing of current records for the Security Council and Atomic Energy Commission, but before very long all the records for meetings in 1946 should be in print.

The official records are issued initially in bilingual editions in English and French and eventually appear also in Chinese, Russian, and Spanish editions.

The official records are sold or exchanged, so that they will be the means for making available to all libraries the bulk of the processed documents in the plenary series, the verbatim records of meetings of the main organs, and the reports of committees and commissions to those main 
organs. The remaining processed documents in the plenary series which are not reissued in the official records are not sold or exchanged, so they must be consulted in the so-called "depository libraries" or at the headquarters of the United Nations. Except for the main committees of the General Assembly and its League of Nations and permanent headquarters committees, it is not intended that summary records of committees and commissions of the councils or of the other ad hoc committees of the General Assembly be published in the official records; likewise the papers of subcommittees will be excluded.

Certain important documents in any series, when they can be prepared sufficiently far in advance of a session, are printed rather than processed, such as the annual report of the Secretary-General on the work of the organization. Reports of commissions to the Economic and Social Council would probably appear only in draft form in the commission series and in final form as printed documents in the council series as supplements to its official records. For example, document E/436, the Report of the Meeting of Experts to Prepare for a $W$ orld Conference on Passport and Frontier Formalities, appears as Supplement No. I to the official records of the fifth session of the council. It seems clear that eventually the major portion of the general documents of the General Assembly and the councils will appear in print, and that an increasingly large part of the key reports will appear initially in printed form in advance of the meeting or session at which they will be considered.

\section{Serial Publications}

In addition to the documents of the United Nations and the official records, there are a number of official serial publications which may here be briefly mentioned. Some of these publications have not yet appeared, while others have not yet acquired that regularity of appearance which marks the transition from the organizing period of the parent body. It is, therefore, fitting that only brief mention be made of them at this time and that, rather, attention be directed at certain aspects of their appearance. The Economic and Social Council was charged by the General Assembly with the task of surveying certain functions and activities of the League of Nations, with a view to determining which of them should, with such modifications as are desirable, be assumed by organs of the United Nations or be entrusted to specialized agencies which have been brought into relationship with the United Nations.

Among such league functions and activities to be considered were certain periodical publications and special studies. The continuance of such publications and the initiation of new series by the United $\mathrm{Na-}$ tions may be undertaken at the headquarters by the appropriate divisions of the Secretariat, by the European office (Geneva), by the office for Asia and the Far East, or by various specialized agencies now or later brought into relationship with the United Nations, with the consequence that existing publications of the agencies must also be considered and that a period of time must elapse before a firm picture can be obtained of the new situation. The Statistical Office of the United Nations at the headquarters now publishes the Monthly Bulletin of Statistics in English and French, which in its new form replaces the former league Monthly Bulletin of Statistics. The Transport and Communications Division of the Department of Economic Affairs prepares the Monthly Review of Important Events in the Field of Transport and Communications in a provisional form for limited distribution which continues the similar publication of the League of Nations 
Economic, Financial, and Transit Department.

Two former publications of the League of Nations library are being continued in Geneva as the Monthly List of Selected Articles and the Monthly List of Books Catalogued in the Library of the United Nations, although not yet on a monthly basis.

The General Assembly approved regulations for the registration of treaties and for their publication in a treaty series of the United Nations. This project is well under way in the Legal Department and will be carried out in the tradition of the League of Nations Treaty Series.

Besides those publications and studies of the League of Nations which are to be continued, and the technical publications and studies inaugurated by the United Nations, is the considerable volume of informational material prepared and planned by the Department of Public Information. The department is well-known to libraries through its United Nations Weekly Bulletin, published in English, French, and Spanish editions. It issues also a wide variety of processed materials for the benefit of the press and schools, and reaches the public through other media less familiar to libraries, such as the radio, still and motion pictures, posters, and public speakers. The full round of its activities is beyond the scope of this paper.

\section{Publications Sales Numbers}

The Sales Section of the Division of Documents and Sales has established a series of standing-order categories for individual publications apart from periodicals and the official records. The categories cover fifteen fields, which are outlined in United Nations Publications Catalogue No. I. Beginning in 1947 each publication carries on the reverse of the title page a box containing a publications sales number consist- ing of the year of publication, the category number of the publication in Roman numerals, and the number of the publication in the particular category in Arabic numerals.

\section{Distribution}

The problem of distributing the unrestricted materials described in this paper may only be touched upon briefly. For the printed materials, the problem is not so difficult, since most of these are obtainable by exchange or sale through arrangements with the regular sales agents of the United Nations. The problem in this field is rather of coordinating the activities of the various specialized agencies and nongovernmental organizations throughout the world which are associated with the United $\mathrm{Na}$ tions, so that at least information concerning separate and serial publications is readily available through some uniform method of listing or cataloging, even though publication and distribution may not be centralized. So far as the processed documents are concerned, it is difficult to see a better solution for a wide distribution to useful purpose of the immense bulk of unrestricted documents (in two working languages) than some arrangement for strategically located "depository libraries." The governments, the delegations, the Secretariat departments, the specialized agencies, and the nongovernmental organizations working with the United Nations must be assured of a distribution of documents sufficient to further their work, but an additional complete distribution beyond a select number of national libraries and research institutions making daily use of such documents seems uneconomic. For the general library, the printed official records will probably suffice. How the documents in the socalled "depository libraries" are to be made available to users elsewhere is a problem for the libraries themselves to solve.

The work of the Documents Index unit 
has so far been chiefly to locate for the delegations and the Secretariat documents currently under discussion in the sessions of the various organs of the United Nationsspeeches, draft resolutions, reports, and the like, to identify documents referred to or quoted, and to bring together documents dealing with any particular subject. The card index files cover a vast range of documents from the San Francisco Conference, through the Preparatory Commission, the General Assembly, the three councils, and the various commissions and other ad hoc bodies established by the main organs, as well as the circulars and bulletins of the Secretariat. But the efforts of a small staff to establish clues to all this material through cards, indexes, and other devices have left little time for publication of upto-the-minute checklists or of detailed subject-indexes. Gradually, however, the backlog of checklists to documents is being whittled away by the issue of individual checklists to each committee series of the General Assembly for 1946. The Documents Index unit also issues at the close of sessions of any organ during 1947, checklists which also list under each agenda item the documents submitted concerning it, the records of meetings in which it was discussed, and the section of the final report concerning the item. These checklists are themselves processed documents, but it is hoped that before the end of the year the unit will be able to publish this material in its own periodic checklist on a sales or subscription basis.

\section{Summary Note}

This survey has been of necessity brief, but it has possibly clarified the picture in some degree, and has suggested some of the documentary questions facing the United Nations and its associated bodies. The magnitude of the problem of international documentation demands that the best of technical skill and imagination be employed toward its solution for the benefit of all peoples. The cooperation and advice of American librarians in meeting this challenge will certainly be both warmly welcomed and expected.

\section{The Library in the Educational Institution}

(Continued from page 5)

be a course in science, it needs a reasonable selection of scientific journals almost as much as it needs its laboratory. An inadequate library means crippled instruction everywhere, because it shuts off the sources of information or of inspiration from teachers, from students, or from both. And apart from formal instruction, the library properly equipped and managed can be the chief intellectual influence on the campus. 